\title{
MÉTODOS PARTICIPATIVOS - ETNOGRAFIA DE UM PROCESSO DE PESQUISA
}

\author{
Participatory methods - ethnography of a research process \\ Métodos participativos - etnografía de un proceso de investigación
}

Marcelo Ernandez, Macedo

Universidade do Estado do Rio de Janeiro

Professor Associado da Faculdade de Comunicação Social

Coordenador do Laboratório de Comunicação Dialógica

marcelo.ernandez@gmail.com

Artur Seidel Fernandes

Bacharel em Ciências Sociais (Uerj)

arturseidel@gmail.com

Jenifer Silva dos Santos

Bacharel em Comunicação Social (Uerj)

Jenifer.silvaa@live.com

\section{Resumo}

Esse artigo tem como objetivo fazer uma análise dos métodos participativos de pesquisa na comunicação e demais ciências sociais. Seu fio condutor é o próprio processo de pesquisa vivenciado pelos autores, que, ao longo do seu desenvolvimento e das dificuldades encontradas, suscita as questões metodológicas discutidas e a busca de referências teóricas para tratá-las. As principais referências utilizadas são os textos organizados por Brandão (1981 e 1984) e a tipologia de pesquisa participativa desenvolvida por Peruzzo (2003). Além dos tipos de métodos participativos discutidos, os autores apontam para questões éticas do processo de pesquisa, tais como as relações entre pesquisados e pesquisadores diante de situações de conflito entre coletivos pesquisados.

Palavras-Chaves: Métodos participativos de pesquisa; Pesquisa de campo; Comunicação Comunitária.

\begin{abstract}
This article aims to make an analysis of participatory methods of research in communication and other social sciences. His leitmotif is the own research process experienced by the authors, who, throughout the development of the difficulties encountered and your, gives rise to the methodological issues discussed and the search of theoretical references to treat them.
\end{abstract}


The main references used are the texts organized by Brandão (1981 and 1984) and the typology of participatory research developed by Peruzzo (2003). In addition to the types of participatory methods discussed, the authors point to ethical issues in the research process, such as the relationship between respondents and researchers on conflict situations between collectives searched.

Keywords: Participatory methods of research; Field research; Community Communication.

\section{Resumen}

Este artículo pretende hacer un análisis de los métodos participativos de investigación en comunicación y otras ciencias sociales. Su leit motiv es el proceso de investigación propia experimentado por los autores que, durante su desarrollo y las dificultades encontradas, plantea los problemas metodológicos discutidos y la búsqueda de referentes teóricos para tratarlas. Las principales referencias que se utilizan son los textos organizados por Brandãow (1981 y 1984) y la tipología de investigación participativa desarrollada por Peruzzo (2003). Además de los tipos de métodos participativos discutidos, los autores apuntan a cuestiones éticas en el proceso de investigación, como la relación entre los participantes y los investigadores en situaciones de conflicto entre colectivos buscados.

Palabras clave: Métodos de investigación participativa; Investigación de campo; Comunicación de la comunidad

\section{INTRODUÇÃO}

Há quatro anos, no início de 2012, foi criado o Laboratório S na Faculdade Y da Universidade $\mathrm{K}$, tendo como objetivos produzir conhecimentos sobre o tema da comunicação comunitária e alternativa e apoiar grupos que trabalham nesse campo. Para alcançar os objetivos propostos, nossa referência metodológica era a pesquisa de campo com observação participante, estratégia utilizada em estudos de caráter antropológico, área de formação principal do coordenador do grupo e de alguns outros membros ${ }^{1}$.

Essa proposta metodológica foi difundida pelo coordenador aos demais membros do grupo, cuja formação é diversificada e multidisciplinar. Há alunos e professores das mais diversas áreas das ciências sociais e humanas. Já passaram pelo $\mathrm{S}$ pesquisadores de comunicação social, ciências sociais, filosofia, história, psicologia e pedagogia. A partir dessa diversidade de formações, esse método apresentou-se mais familiar junto àqueles formados ou em formação na área de ciências sociais. A maioria dos outros pesquisadores traz referências vagas sobre o método antropológico de pesquisa.

\footnotetext{
${ }^{1}$ Para saber sobre os fundamentos da pesquisa de campo com observação participante ver Malinowski (1976).
} 
Não obstante tivesse o método antropológico como referência, incomodava ao coordenador do grupo o impacto limitado que os estudos na área tendem a ter sobre os grupos pesquisados. Na verdade, pode-se dizer que esse fenômeno não é uma particularidade da antropologia, mas uma tendência geral dentro do universo da pesquisa nas ciências sociais e humanas. Os resultados das pesquisas em geral circulam somente dentro do universo acadêmico, entre os pares da área de conhecimento, com pouca divulgação e resultados para os grupos pesquisados, para agentes do Estado e para a sociedade como um todo.

No entanto, não tínhamos referências metodológicas para conjugar o método antropológico com essa perspectiva política mais atuante. A princípio, parecia haver uma certa contradição entre o distanciamento necessário para o trabalho antropológico e essa perspectiva mais engajada. Isso, de fato, se apresenta como uma questão para a literatura sobre métodos de pesquisa em ciências humanas e sociais? Que problemas poderíamos vir a enfrentar em decorrência dessa contradição? Enfim, como proceder diante dessa contradição? Essas eram algumas questões que estavam latentes em nossa proposta metodológica e que, como veremos, somente o próprio processo de trabalho nos permitiu responder. Foi somente vivenciando os problemas decorrentes dessa contradição, que pudemos perceber suas dimensões e, a partir daí, buscar referências bibliográficas para resolvê-los.

O objetivo deste artigo é fazer uma análise dos métodos participativos de pesquisa nas ciências sociais e, em especial, na comunicação. Para tal, discorreremos sobre nosso próprio processo de pesquisa, partiremos de uma perspectiva etnográfica do nosso próprio trabalho.

\section{O ARTIGO}

Foi numa visita ao curso de Comunicação Comunitária na Universidade $\mathrm{K}$, que conhecemos Helena ${ }^{2}$. A nosso convite, ela veio falar sobre o jornal comunitário que editava e os desafios deste tipo de comunicação. Helena morava em um conjunto de favelas e há alguns anos era editora de um dos dois jornais comunitários que ali circulavam. O Jornal de Helena era o mais antigo, sendo bastante reconhecido dentro e fora desse território. Não obstante, naquele momento, o Jornal passava por dificuldades, estava sem circular havia alguns meses por escassez de recursos. O grupo que um dia já trabalhou de forma remunerada e que, durante algum tempo, conseguiu manter o trabalho de forma voluntária, havia se

\footnotetext{
${ }^{2}$ Helena é um nome fictício para preservar sua real identidade.
} 
desmobilizado. Um último número do jornal chegou a ser publicado, mas não foi distribuído por falta de recursos.

Diante deste cenário, propusemos a Helena uma parceria entre o Laboratório $\mathrm{S}$ e o Jornal. Nessa parceria, manteríamos, pelo menos, um estagiário para auxiliar na reestruturação do jornal e nos colocamos à disposição para o que mais fosse necessário. Helena aceitou a proposta. Uma das estudantes de graduação do S se interessou em participar do jornal e o contato entre nós e o Jornal rapidamente se estreitou. Oferecemos um segundo estagiário e colaboramos ativamente na realização de um curso de Comunicação Comunitária, promovido pela Ong que abriga o Jornal, com vistas a reestruturar sua equipe.

Ao mesmo tempo, no segundo semestre de 2012, colaboramos ativamente com Helena para a realização do Primeiro Seminário Regional de Comunicação Comunitária, que veio a ser realizado a partir de recursos obtidos pelo $\mathrm{S}$ junto à Fundação de Amparo à Pesquisa T. A partir deste Seminário, a própria Helena e outros militantes de outros veículos ingressaram no Laboratório S. Desde então, o S abrigou militantes da comunicação social e estes passaram também a atuar como pesquisadores. Esses novos membros também deveriam escrever cadernos de campo e ajudar a sistematizar o conhecimento sobre os próprios veículos dos quais participavam. A interface entre as dimensões da pesquisa e a militância ganhava novos ingredientes.

Embora houvesse um interesse comum pelo tema, os objetivos específicos eram distintos entre pesquisadores e militantes. Mesmo havendo cordialidade e um clima de colaboração nas reuniões do $\mathrm{S}$, os primeiros se mostravam mais preocupados com sua formação acadêmica e com a produção de conhecimento, e os demais direcionavam suas atenções para a superação dos desafios enfrentados por seus veículos. Isso se expressava em modos distintos de participação, que era voluntária para todos, com exceção de ou outro bolsista. Enquanto os pesquisadores se mostravam mais presentes nas discussões de textos, os militantes preferiam o debate sobre os casos estudados. Assim como nos veículos de comunicação comunitária, no $\mathrm{S}$, o caráter voluntário das atividades também se constituía em um problema operacional, que gerava descontinuidades e desencontros ao trabalho ${ }^{3}$.

O Seminário foi bem sucedido. Alcançamos os nossos objetivos de discutir em profundidade as principais questões da Comunicação Comunitária e ampliamos a nossa rede nessa área. $\mathrm{O}$ curso promovido por Helena também obteve bons resultados, a equipe do Jornal

\footnotetext{
${ }^{3}$ Naquela época contávamos com apenas um bolsista de graduação. Hoje contamos com cinco bolsistas de graduação e um de ensino superior.
} 
foi reformulada e, a partir daí, um número foi editado, já com a nova equipe. Nossa parceria estava cada vez mais fortalecida e já era hora de gerarmos os primeiros frutos com os conhecimentos acumulados até ali nas pesquisas de campo. Após o primeiro artigo conceitual sobre o tema, quando Helena ingressou no S, já estávamos escrevendo um segundo artigo que apresentaria os primeiros resultados do trabalho de campo junto ao jornal comunitário editado por ela. Decidimos abordar, nesse segundo artigo, o tema da sustentabilidade de um jornal comunitário, problema recorrente nesse universo e para o qual o Jornal de Helena era um ótimo caso para análise. Desde o início, ficou combinado que os autores deste artigo seriam o coordenador do $\mathrm{S}$ e os dois estagiários que trabalhavam no Jornal.

Assim como o primeiro artigo, este segundo texto também foi amplamente discutido no $\mathrm{S}$ antes de ser enviado para publicação. Mas, dessa vez, diferente da primeira, havia questões éticas delicadas a serem debatidas e resolvidas. Ao mesmo tempo em que a imagem da Ong e do Jornal precisavam ser resguardadas, alguns problemas importantes do universo da comunicação comunitária que costumam ser negligenciados pela bibliografia sobre o tema precisavam ser descobertos para a produção de conhecimento significativo na área. O desafio era tratar desses problemas sem expor o Jornal e sua instituição mantenedora. Inclusive, um desses problemas residia exatamente nos conflitos entre estes.

A presença de Helena nesses debates sobre o artigo era importante. Por ser editora do Jornal há alguns anos e, ao mesmo tempo, ter participado de vários de nossos debates sobre os desafios da Comunicação Comunitária, seria ela a encarregada principal de verificar a correção das informações sobre o jornal e, principalmente, avaliar como dizer o que precisava ser dito sem afetar imagens. Helena sugeriu, juntamente com outros membros, diversas modificações para resguardar a imagem de envolvidos e estas foram amplamente acatadas.

Após uma série de transformações, uma última versão do artigo foi submetida para a apreciação dos membros do S, que o aprovaram. O texto foi enviado para publicação. Apesar da aprovação formal, Helena não estava satisfeita, o que pode ser percebido pela mensagem: “eu já li, tenho minhas observações, mas vou deixá-las guardadas. Vou respondê-las de uma outra forma." Embora parecesse satisfeita com a resolução dos dilemas éticos que envolviam o artigo, era perceptível o incômodo da editora com o tom deste, que ela classificava como "pessimista". Por parte dos autores, não havia preocupação em se mostrar otimista ou pessimista sobre o futuro do Jornal, sobre o qual não sabíamos e não especulávamos no artigo. Entendíamos que o nosso dever era, a partir da descrição de um caso concreto, tratar dos problemas da comunicação comunitária iluminados por este caso. No entanto, não 
soubemos dar a devida atenção à insatisfação de Helena. Aquela mensagem ficou sem resposta e o trabalho prosseguiu.

\section{O PROJETO DO FILME}

Enviado o artigo, o próximo assunto a ser debatido com maior atenção no $\mathrm{S}$ era o projeto de filme que vínhamos formulando. A idéia do filme, a princípio, era documentar determinados grupos de comunicação dialógica e, ao mesmo tempo, construir um panorama crítico da concentração dos meios de comunicação no Brasil, comparando essa realidade com outros países da América Latina. O objetivo era mostrar como esse assunto ainda é pouco debatido na sociedade brasileira, enquanto países vizinhos têm promovido avanços substanciais nessa área.

Procuramos definir os grupos que seriam documentados e o jornal de Helena era cogitado como um dos veículos mais interessantes, tanto pela sua importância no território em que atuava, como pela trajetória pessoal da sua editora. Na primeira versão do projeto enviado pelo coordenador ao grupo, não havia ainda uma metodologia de filmagens definida, mas apenas uma ideia geral sobre o seu conteúdo. Não obstante, estava implícito que a realização do filme se daria como um processo análogo ao que desenvolvíamos nos artigos. A ideia era basear-se nas experiências de campo e captar imagens e depoimentos que expressassem aquilo que acreditávamos ser significativo para o debate sobre a democratização da informação. O filme seria fruto do nosso encontro com os grupos escolhidos como "personagens", seria resultado desse encontro. A proposta era que todas as etapas de sua construção seriam debatidas entre todos os envolvidos, tanto os membros do Laboratório como os próprios sujeitos filmados.

Após debate, os membros do $\mathrm{S}$ definiram quatro grupos de mídia para serem abordados no filme e o Jornal que Helena editava estava entre estes. A equipe se concentrava em concluir o projeto do filme, quando as divergências metodológicas se explicitaram. Um dos membros da equipe criticou o projeto do filme por considerá-lo não dialógico, na medida em que o seu argumento teria sido construído sem consulta aos grupos que seriam retratados. Em suas palavras, dizia que seria um filme "para" os grupos e não um filme "com" os grupos. Nesse sentido, ele sugeriu que registrássemos um encontro da nossa equipe com os grupos reunidos, já em cena, para que todos juntos desenvolvêssemos uma idéia coletiva do que seria o filme. Esse primeiro registro, de acordo com sua ideia, seria integrado à montagem final. 
Essa proposta sofreu resistência do proponente do projeto e dúvidas de outros membros. O proponente entendia que essa proposta colocaria em risco um dos pilares do projeto, qual seja, a diversidade de representações sobre o universo da comunicação comunitária. Ao reunir os sujeitos que seriam filmados, haveria uma tendência de homogeneização dos discursos e toda a riqueza da diversidade ficaria comprometida. Argumentava também que os conteúdos a serem tratados no filme não seriam escolhidos a esmo, mas sim a partir de três anos de pesquisa sobre o tema, ou seja, o objetivo era expressar alguns resultados de uma trajetória de pesquisa considerável do $S$; e que os conteúdos de interesse dos sujeitos filmados seriam tratados ao longo do processo de filmagens, não sendo necessário reuni-los para perguntar-lhes que filme fazer. Enfim, a proposta da reunião, embora válida para explicitar os pressupostos dialógicos do Laboratório, resultaria em outro filme, bem diferente daquele que estava sendo proposto.

Essas questões, por si só, pareciam perfeitamente equacionáveis e acreditávamos que chegaríamos a um consenso. Mas, não foi o que aconteceu. As divergências se misturaram a outras questões relacionadas à condução do trabalho no Laboratório, ganharam contornos mais amplos e radicalizaram-se em questões pessoais que resultaram na saída de três membros do grupo: Helena e dois outros que se colocaram ao lado dela na discussão metodológica. Isso porque, conforme percebemos apenas depois, essas discordâncias aparentemente superficiais, quando exploradas a fundo, revelariam compreensões muito distintas e até incompatíveis sobre aspectos fundamentais do nosso trabalho, tais como os métodos participativos de pesquisa, o nosso papel enquanto pesquisadores e a construção de um conhecimento dialógico, tanto interna - entre os membros do Laboratório - quanto externamente - entre o Laboratório e os grupos parceiros ou representados em pesquisas. Vários desses pontos de conflito já haviam sido, em algum momento, objeto de discussão e parecia haver perfeita concordância em relação a eles. Foi possível perceber que esses dilemas concretos, surgidos na prática da pesquisa, demandaram uma revisão dos nossos princípios gerais, que antes pareciam configurar-se como um acordo estável, unânime e, em certos casos, até evidente para os membros da equipe.

\section{SOBRE AS VÁRIAS FORMAS DE PARTICIPAR NA PESQUISA}

Já havia a proposta de estudar e discutir metodologia de pesquisa no $\mathrm{S}$, antes de eclodirem os conflitos. Mas, foi a partir dos debates sobre o artigo e sobre o filme que tornou- 
se urgente recorrer a novas referências metodológicas, até para que fosse possível compreender melhor as posições diferentes já assumidas dentro do grupo.

A partir daí, em contato com a bibliografia sobre o tema, descobrimos que diversos autores das décadas de 1970 e 1980 já haviam questionado a falta de resultado político efetivo na maioria das pesquisas de observação participante clássica. Nosso incômodo inicial, portanto, já havia sido tematizado como um problema metodológico por pesquisadores dessa geração.

As coletâneas "Pesquisa Participante" (1981) e "Repensando a Pesquisa Participante" (1984), organizadas por Carlos Brandão, foram fundamentais para conhecermos melhor o que alguns desses autores estavam propondo enquanto método e concepção de ciência. Reunindo textos do próprio organizador, além de autores como Paulo Freire (1981) e o colombiano Orlando Fals Borda (1981), as coletâneas pautam uma rejeição ao paradigma científico da neutralidade e do distanciamento objetivista. A partir dessa crítica, são relatadas diversas experiências em que os interesses da pesquisa são subordinados aos interesses dos grupos ou temas a serem pesquisados ${ }^{4}$.

Preocupado com a inutilidade ou o mau uso político de pesquisas sociais contemporâneas, Brandão reivindica uma ciência pautada pela prática política e pelo compromisso popular. É a partir dessa perspectiva que ele define a pesquisa participante, com apontamentos que não são baseados em práticas predominantes nas pesquisas sociais, mas que aparecem como elementos de uma "ciência nova", que desponta em trabalhos como o dos autores ali reunidos.

O autor parece reconhecer que, de certa forma, pelos procedimentos da observação participante, pesquisador e pesquisado trabalhariam juntos na construção de um saber, ainda que em situações, tarefas e pontos de vista bem distintos. Sua preocupação é como a prática e os pressupostos das pesquisas realizadas com esse método engendram determinados usos do saber. Ele questiona como, apesar de haver algum nível dialógico na construção desse conhecimento, os fins e os usos desses saberes, e toda sua relação com a transformação social, não são pautados pelos grupos eleitos como objetos de pesquisa.

Mesmo as pesquisas de "realidade social", comprometidas com projetos de transformação, cairiam no erro de reafirmar a divisão do trabalho científico entre dois lados opostos: “o lado 'popular' dos que são pesquisados para serem conhecidos e dirigidos, versus

\footnotetext{
${ }^{4}$ Sobre a crítica ao paradigma obejtivista pode-se buscar também na antropologia Clifford (1986) e Wagner (2010).
} 
o lado 'científico', 'técnico' ou 'profissional' de quem produz o conhecimento, determina seus usos e dirige "o povo" (Brandão, 1981:10). Assim, a própria ideia de "objeto de pesquisa" implicaria, apesar de sua aparente neutralidade, a subordinação daqueles cuja "realidade" se procura conhecer. Sendo objetos de pesquisa seriam, também, objetos da história.

Em relação aos grupos pesquisados, enquanto a noção de "objeto" identifica categorias abstratas e controladas (uma "comunidade", o "popular", o "marginal”, o "indígena", o “camponês" etc.), a posição de sujeito é vista como emancipatória e deflagradora dos conflitos sociais. A partir da prática concreta de grupos cuja "realidade" foi objetificada pela ciência, deu-se a descoberta de que eles devem "conquistar o poder de serem, afinal, o sujeito, tanto do ato de conhecer de que têm sido o objeto, quanto do trabalho de transformar o conhecimento e o mundo que os transformaram em objetos" (Brandão, 1981:11).

Em relação ao papel do pesquisador, a noção de sujeito, quando em oposição a um objeto, carregaria pretensões de neutralidade e isenção. Talvez, por isso, Brandão valorize a ideia de um agente da pesquisa, cuja legitimidade se ancora em outros aspectos, que se resumem no compromisso de pesquisar classes populares com o intuito de servir a prática política dessas classes.

Desses apontamentos, decorre uma série de problemas para as pesquisas participativas, dos quais trataremos a seguir. Vale ressaltar que a posição de Brandão é muito clara:

"A participação não envolve uma atitude do cientista para conhecer melhor a cultura que pesquisa. Ela determina um compromisso que subordina o próprio projeto científico de pesquisa ao projeto político dos grupos populares cuja situação de classe, cultura ou história se quer conhecer porque se quer agir" (Brandão, 1981:12).

É evidente, portanto, que a subordinação da pesquisa aos interesses concretos do grupo pesquisado é reivindicada por Brandão como um pressuposto que deve, de agora em diante, definir os procedimentos das pesquisas participativas. Não se trata de uma variação ou uma possibilidade, muito menos de uma alternativa a esta. Trata-se da fundação de um modelo de pesquisa participativa pautada por uma nova ciência do homem (expressão repetidamente utilizada por outros autores da coletânea) e de um descarte radical das concepções científicas de neutralidade, isenção, distanciamento e objetividade.

Percebíamos, então, que a articulação das nossas experiências com a perspectiva de Freire visava à construção de saberes de cunho coletivo e popular, que pressupunham agentes de pesquisa, cujas características seriam uma imersão prévia e um pertencimento pleno a 
esses grupos, o que inviabilizava a ideia convencional da observação participante proposta pela antropologia, a partir da qual se pressupõe um movimento de afastamento tão importante quanto o de aproximação. Mesmo reconhecendo as potencialidades dessa perspectiva, nos pareceu que ela era fundada em relações bem diferentes daquelas que o Laboratório poderia construir em curto prazo. Brandão fala de pesquisadores constituídos no seio dessas experiências ou plenamente reconhecidos por elas, que apostam fundamentalmente no seu pertencimento a esses grupos para construir conhecimento. Se nosso objetivo é abordar o tema da comunicação comunitária, que envolve um conjunto extenso e complexo de experiências engajadas politicamente, como poderíamos pautar nossa perspectiva de pesquisa por esses termos? Não cairíamos no risco de assumir uma posição - essa sim perversa - de emular uma dialogia? Ou de fazer uma adesão automática e acrítica aos posicionamentos políticos assumidos pelos grupos pesquisados?

Indagamo-nos sobre nosso papel como pesquisadores e sobre que posição assumir diante dos grupos pesquisados. Como foi dito, o $\mathrm{S}$ é composto por um grupo de formação bastante heterogênea, assim como é o campo de experiências sobre o qual pretendemos nos debruçar. As experiências de comunicação dialógica, além de muito diferentes entre si, são orientadas por perspectivas políticas distintas e frequentemente conflitantes ou contraditórias umas com as outras. Embora a militância seja uma constante, ela se manifesta por estratégias, posicionamentos e pautas que não se articulam em torno de um único ideal ou de um inimigo comum necessariamente.

Percebemos, então, que se nossa aproximação com cada grupo envolvesse um comprometimento imediato com seu posicionamento político, cairíamos em inúmeras contradições e, provavelmente, nosso problema maior seria administrar frentes de militância, ao invés de produzir conhecimento qualificado na área, esse sim, nosso objetivo fundamental. Ficava claro a essa altura algo que, em teoria, todos já havíamos aprendido: o problema da falta de impacto político das pesquisas não poderia ser resolvido com a adesão dos pesquisadores às posições políticas dos grupos de comunicação.

Se a pesquisa em si poderia ser prejudicada, a contribuição para esses grupos também se revelaria questionável. Qual seria nosso papel se apenas endossássemos as proposições já formuladas pelo ativismo político desses grupos? Identificamos o risco de reforçar uma lógica segundo a qual o cientista social dá legitimidade a discursos já estruturados por esses grupos sociais, como se eles dependessem de nós para isso. Na verdade, nas sociedades contemporâneas, com grande complexidade do trabalho social, diversos atores da sociedade 
civil organizada atuam propositivamente, disputando discursos sobre as dimensões econômicas e simbólicas da sociedade. É por essa perspectiva que nos debruçamos sobre o universo da comunicação comunitária. É importante respeitar (e de certa forma valorizar) a capacidade do outro de falar por si. Um membro de muitos anos do jornal de Helena, por exemplo, produziu uma dissertação de mestrado sobre sua experiência no jornal, enfatizando sua experiência pessoal e defendendo as posições deste.

Por essas razões, a proposta metodológica de Brandão pareceu-nos útil como uma possibilidade de método de pesquisa a ser considerada em situações em que há profundas relações e unidade ideológica entre os envolvidos no processo de pesquisa. Mas, por um lado, revelou-se inadequada para nosso contexto de pesquisa, caracterizado por um universo altamente diversificado política e ideologicamente. Por outro, não nos serviu plenamente como resposta às questões que nos afligiam sobre a tensão entre os compromissos científicos de pesquisa e o desejo de contribuir de modo mais efetivo com o campo. Além disso, não poderíamos aceitar, também por essas razões, a redução dos métodos participativos a esse modelo ali proposto, como se essa fosse a única maneira válida de fazer pesquisa participativa e como se de qualquer outra forma estivéssemos inviabilizando a possibilidade de dialogia. Nosso contexto era bem diferente e precisávamos revisitar outros conceitos sobre esses métodos e sobre a construção dialógica de conhecimento.

Como já pontuamos, estudos sobre antropologia de grupos urbanos resgatavam o princípio de que o conhecimento antropológico depende da experiência da alteridade. Considerando que, nas chamadas sociedades complexas, existem amplas redes de interações e uma série de aspectos culturais compartilhados de forma generalizada (a língua talvez seja o primeiro deles), grande parte da dificuldade de pesquisa é exatamente conseguir se distanciar dos sujeitos pesquisados. Os grupos sociais, nas cidades, constituem um "outro" bem diferente daquele povo isolado e distante do pesquisador sobre o qual narrava Malinowski (1976). Enquanto para este aproximar-se era o desafio e a distância era o ponto de partida natural, na pesquisa de grupos urbanos a relação se inverte, e a ênfase é exatamente em distanciar-se, estranhar o que é cotidiano (VELHO, 1987).

Esses trabalhos revisitaram e adaptaram os métodos de pesquisa participativa, considerando essas outras dimensões. É interessante aqui observar que Malinowski formula sua teoria no contexto da teoria funcionalista, que procurava explicar as culturas estudadas como sistemas fechados, totalidades coerentes. Observando as reapropriações desse método, notamos como a pesquisa participante ganhou contornos bem diferentes com o 
desenvolvimento do campo da antropologia urbana e a consolidação, em diversos campos, da predominância de perspectivas micro-sociológicas, marcadas por um paradigma compreensivo, com ênfase na interpretação, nos atores e nas interações sociais.

Para nossos problemas práticos de pesquisa, era preciso estabelecer, por ora, referências que distinguissem os diversos tipos de pesquisa participativa. Então, foi somente a partir de um artigo de Cicilia Peruzzo (2003) sobre os principais aspectos teóricometodológicos acerca da participação na pesquisa e suas diferentes modalidades, que percebemos que há certa confusão no campo da comunicação e, de modo mais amplo, das ciências humanas e sociais como um todo, no uso de termos como "observação participante", "pesquisa participante" e "pesquisa-ação" e as distinções entre estas propostas metodológicas. Esse artigo foi fundamental para descobrirmos as referências que buscávamos entre os incômodos da falta de impacto político da observação participante e os exageros do militantismo por meio da pesquisa.

Peruzzo (2003) define que haveria três formas de participação na pesquisa. A primeira, a "observação participante", que prevê a participação do pesquisador no cotidiano dos sujeitos pesquisados, sem a necessidade de qualquer retorno dos resultados da pesquisa a estes. Esse seria o método clássico da antropologia, sugerido por Malinowski e aperfeiçoado ao longo do século passado. Mesmo que essa proposta, atualmente, pressuponha algum retorno dos pesquisadores aos grupos pesquisados, o mais importante a destacar nessa proposta metodológica e que a diferencia das outras é que não há qualquer participação dos grupos pesquisados nas decisões sobre como a pesquisa está sendo conduzida. O retorno aos sujeitos pesquisados, quando ocorre, é para apresentar resultados.

A segunda forma de participação na pesquisa seria a "pesquisa participante". Essa proposta prevê uma troca um pouco mais direta e equânime entre pesquisadores e os sujeitos pesquisados, na medida em que estes últimos poderiam fornecer sugestões e debater o processo de pesquisa com os primeiros, embora as decisões finais e a autoria da pesquisa caibam ainda a estes. Além disso, esse método prevê que, necessariamente, deve haver o debate dos resultados de pesquisa com os grupos pesquisados, já que seriam estes os principais interessados nesse processo de aprendizagem coletivo.

A terceira forma de participação em pesquisas seria aquela reconhecida como pesquisa-ação. Nesse método, pesquisados e pesquisadores já não são distinguíveis, misturam-se e formam um único grupo. Essa proposta prevê que todo o processo de pesquisa seja concebido, desenvolvido e avaliado em conjunto entre pesquisadores e sujeitos 
pesquisados. Segundo essa concepção, somente dessa forma se alcançam os problemas que realmente afligem grupos, sendo o próprio processo de pesquisa o método de ação, portanto, superação das dificuldades percebidas.

Apesar dos equívocos e ambigüidades produzidos na área, todos esses modelos de pesquisa são, a rigor, "participantes", na medida em que envolvem a imersão do pesquisador na prática específica de um determinado grupo e têm como pressuposto que é essa imersão que possibilitará uma compreensão do olhar do outro. Dessa forma, a construção de um sentido inteligível e estruturado de uma determinada realidade, ainda que formulado somente pelo pesquisador, será fruto de um esforço de compreensão da visão de mundo daquele grupo, através da imersão nas suas atividades cotidianas. Será fruto, enfim, de um encontro entre pesquisador e grupo.

\section{O FILME}

Os problemas vividos durante a discussão do projeto do filme e o consequente contato com o referencial metodológico exposto acima trouxeram novas perspectivas para a realização do filme. Quando iniciamos as filmagens já sabíamos que, além da observação participante, há pelo menos duas outras formas de desenvolver uma pesquisa de forma participativa: a pesquisa participante e a pesquisa-ação. A partir do contato com o livro organizado por Brandão e com o artigo de Peruzzo, percebemos que nossa proposta metodológica era bastante próxima daquela definida por essa autora como "pesquisa participante". Nosso modo de fazer antropologia previa não somente a coleta de dados, seu tratamento e a elaboração de produtos acadêmicos, mas a troca permanente de conhecimentos ao longo do processo de pesquisa; e, o que nos parece fundamental, o retorno para o debate com os sujeitos pesquisados destes produtos gerados. Diferente da proposta da pesquisa- ação, entendíamos também fundamental o controle sobre o processo de pesquisa ou, em outras palavras, a manutenção da autonomia sobre a nossa própria produção. Da mesma forma que os veículos com os quais nos relacionávamos tinham autonomia sobre seus conteúdos publicados, achávamos que também deveríamos ter em relação a nossa própria produção.

Foi com esses pressupostos metodológicos que desenvolvemos o projeto do filme. Em meados de 2014, obtivemos financiamento para executar o projeto e, partir daí, mesmo com recursos limitados, percebemos que poderíamos desenvolver a ideia proposta. O projeto inicial pretendia acompanhar, durante um ano, o cotidiano de quatro grupos de comunicação 
comunitária ou alternativa. Esses quatro grupos estavam localizados em diferentes pontos da região metropolitana do Rio de Janeiro, o que implicava significativos esforços de deslocamento; e, até então, tínhamos tido contato mais frequentes apenas com dois deles, que já eram parceiros do S. Em relação aos outros dois, o contato era ainda embrionário, ou seja, esses grupos não conheciam a fundo o nosso trabalho, seria necessária a criação de laços de confiança no decorrer do processo.

A efetivação dessa proposta de acordo com os pressupostos antropológicos para o registro audiovisual em uma pesquisa de campo deveria prever quatro equipes munidas de equipamentos para o trabalho. $\mathrm{O}$ ideal era que tais equipes passassem a conviver diariamente junto a esses grupos. Mas, devido à agenda de aulas dos alunos e às longas distâncias diárias a serem percorridas para esse acompanhamento, não havia a possibilidade de um acompanhamento cotidiano. A solução encontrada foi a criação de duas subequipes que, de forma alternada, utilizariam o único equipamento de filmagem disponível ao longo do ano. $\mathrm{O}$ fato é que, desde o início, os pressupostos metodológicos da pesquisa de campo com observação participante estavam sendo afetados. Ao longo de todo o processo, pudemos realizar algo entre o que é recomendado em termos do método antropológico da pesquisa de campo - a imersão no cotidiano pesquisado - e o que é convencionalmente realizado em projetos cinematográficos - a pesquisa pontual para colher informações básicas e identificar personagens.

Além dessas limitações de recursos, o caráter dinâmico do trabalho destes grupos e a ausência de relações prévias com um destes dificultaram também essa imersão. Refiro-me aí, principalmente, ao grupo que atuava fazendo transmissões ao vivo pela internet, que chamaremos aqui de grupo X. Esse grupo não viu com bons olhos que um membro de nossa equipe passasse duas tardes em sua sede - que era também local de moradia daquelas pessoas - acompanhando o seu cotidiano. Não ficou muito claro para nós o motivo deste desconforto, mas pareceu tanto a necessidade de manter a privacidade dos habitantes da casa quanto a tentativa de não revelar determinadas informações consideradas confidenciais sobre o trabalho.

Mesmo com todas essas limitações, o começo do processo de filmagens foi animador. Logo conseguimos identificar personagens carismáticos e com trajetórias de vida significativas para representar os grupos dos quais eram parte. Ao longo do tempo, fomos ganhando familiaridade com os sujeitos pesquisados/filmados e as relações pessoais entre nós estreitando-se. As relações, até certo ponto formais, deram lugar a conversas descontraídas e 
brincadeiras. Mas, a verdade é que não chegamos a fazer uma imersão junto ao cotidiano de nenhum dos quatro grupos. Nos aproximamos um pouco mais disso em relação a dois dos grupos: uma rádio comunitária, junto a qual fizemos seguidas visitas nas manhãs de sábado para o acompanhamento de um programa de entrevistas apresentado pelo seu coordenador, personagem principal desse grupo na rádio e no filme; e um coletivo de mídia, educação e cultura, junto ao qual passamos algumas tardes acompanhando oficinas de formação de jovens em hip hop e realizando entrevistas. Nesses casos, adquirimos a densidade característica da pesquisa antropológica, conseguindo compreender o cotidiano daqueles grupos em suas várias dimensões e contradições.

Já estávamos pesquisando e filmando há mais de seis meses quando vimos a necessidade de reorientar a proposta inicial. Embora com boas relações e personagens relativamente densos, não tínhamos obtido material fílmico que revelasse as contradições inerentes a cada um destes grupos. Embora soubéssemos que a vida destes grupos era cercada por tensões, estas não estavam presentes no material filmado. E, naquele momento, especialmente um grupo vivia grandes conflitos: o grupo X. Esse grupo era acusado por outros de se beneficiar por suas relações políticas com o partido que, então, assumia o governo federal e por adotar práticas contrárias ao discurso da horizontalidade na gestão - um dos princípios do midiativismo - definido aqui como aquele universo dos grupos que produzem conteúdos para a internet.

Soubemos dessas acusações mais ou menos na mesma época que tivemos duas experiências frustrantes de produção de imagens em parceria com o grupo X. Diante dessas acusações e experiências ruins, vimos a necessidade de incluir novos grupos no projeto, já que o grupo X não parecia representativo do seu universo. Esse grupo estava em um campo de ação política distinto de diversos outros grupos que desenvolviam trabalhos significativos na área. Foi a partir do contato e das sugestões de uma professora da Universidade $\mathrm{K}$, que também veio a ser personagem do filme - na medida que teve a sua trajetória duramente afetada pela mídia convencional -, que decidimos incluir outros três grupos de midiativismo, que chamaremos aqui de $\mathrm{Y}, \mathrm{Z}$ e W. Esses grupos faziam oposição clara e aberta ao grupo $\mathrm{X}$; sabíamos de discussões envolvendo um membro do grupo $\mathrm{X}$ e um membro do grupo $\mathrm{Y}$, ambos personagens do filme; e tínhamos também notícia que esse mesmo membro do grupo $\mathrm{X}$ e um componente do $\mathrm{Z}$ já haviam chegado ao pugilato. Portanto, do ponto de vista da relação política entre os grupos, nos colocamos em uma situação delicada. Estávamos acompanhando, ao mesmo tempo, grupos que eram inimigos entre si em nome da geração de 
conhecimento sobre um universo novo, atraente e de suma importância em diversos sentidos, sobretudo o político, já que a atuação desses grupos de midiativismo estava revelando as contradições do discurso midiático e estimulando a atuação de uma série de movimentos sociais.

Quais são os limites éticos para a pesquisa nessas situações? Como manter o bom relacionamento com grupos que eram inimigos declarados e que, ao mesmo tempo, advogavam em seu trabalho a tomada aberta de posição politica, em detrimento do discurso da imparcialidade, característico da mídia convencional? Seria o caso de abdicar desse trabalho?

Seguimos em frente, procurando ouvir as posições em conflito, sem tomar partido de algum dos grupos, o que só foi possível por não estarmos imersos nesse universo. Se, por um lado, um certo distanciamento em relação aos grupos nos prejudicou, por outro lado, em relação a isso, nos ajudou. A ideia de apresentar um panorama da concentração midiática na América Latina, também pela falta de recursos, não se desenvolveu. Decidimos ampliar esse debate em um outro projeto a ser desenvolvido posteriormente. Em suma, o projeto inicial de incluir quatro grupos nacionais e, possivelmente, alguns de outros países se transformou em um projeto que trataria apenas do caso brasileiro, com sete grupos. Rapidamente, adquirimos proximidade com esses três grupos que entraram no projeto. Isso nos custou algum estranhamento em relação ao grupo $\mathrm{X}$ assim que este percebeu essa proximidade, mas nada que comprometesse seriamente a nossa atuação.

O material ganhou densidade e, aos poucos, os conflitos e contradições deste universo que procurávamos foram sendo revelados. Embora mais comedido em suas intervenções, o personagem principal do grupo $\mathrm{X}$ aos poucos foi tendo que se posicionar diante das delicadas questões que fomos inserindo nas entrevistas. Com muita habilidade, ora se esquivava destas questões, ora falava da posição do seu grupo sem prejudicar a imagem de outros. Já os grupos $\mathrm{Y}, \mathrm{Z}$ e W faziam críticas abertas ao grupo X, faziam questão de evidenciar sua oposição. Para nós, tudo isso seria resolvido na ilha de edição. Nossa intenção era revelar os conflitos, mas sem afetar imagens ou acirrar as disputas. Pelo contrário, sabíamos da importância do trabalho de todos os grupos e acreditávamos que essas disputas eram prejudiciais e poderiam ser superadas.

Conforme imaginado durante as filmagens, tivemos intensos debates durante a elaboração do roteiro de edição para decidir como apresentar no filme os conflitos e contradições de forma ética, sem prejudicar imagens ou mesmo tomar uma posição favorável 
a um ou outro grupo. Em relação a este último ponto, como havia um claro e aberto conflito entre os grupos, seria muito difícil que a edição agradasse a todos, tínhamos consciência disso. A escolha de cada plano ou fala significava de alguma forma ampliar ou reduzir o discurso de um ou outro lado. Mesmo ciente dessa ausência de imparcialidade, e seguindo os pressupostos metodológicos weberianos (Weber,1997), nos empenhamos em manter uma certa isenção no sentido de não revelar nomes nas situações em que eram feitas acusações, mas apenas as categorias acusatórias. O que nos parecia relevante para a construção do conhecimento na área era do que cada grupo ou individuo era acusado, mas não quem eram os alvos destas.

Conforme os pressupostos da pesquisa participante (PERUZZO, 2003), antes de lançar o filme, o enviamos para todos os personagens para que estes fizessem sugestões, comentários e, principalmente, se havia algo que fosse considerado eticamente inadequado. Não recebemos nenhum comentário dos personagens e poucos de alguns outros colegas que também o receberam.

O lançamento do filme ocorreu em uma das duas salas de cinema da Zona Norte da cidade em que ele veio a entrar em cartaz. Todos os grupos que participaram do filme e mais alguns outros foram convidados. Todos os grupos participantes enviaram pelo menos um representante. A presença dos sujeitos pesquisados/personagens do filme no lançamento foi a maior legitimidade que poderia ser fornecida ao trabalho. Não obstante, o grupo X enviou apenas um representante que nunca havia tido qualquer contato conosco. Tratava-se de um jovem que havia acabado de entrar no grupo. Tivemos vários contratempos naquela noite, a sessão começou atrasada e, por isso, o tempo para o debate do filme foi reduzido. Apenas alguns dos personagens tiveram a oportunidade de falar. $\mathrm{O}$ clima foi de exaltação ao trabalho realizado.

Algumas semanas depois, quando o filme já havia saído de cartaz e realizávamos exibições programadas, percebemos que o grupo $\mathrm{X}$ não havia ficado satisfeito com $\mathrm{o}$ resultado. Exibimos uma versão reduzida do filme em uma ocupação de um prédio da administração pública federal na qual havia vários representantes do grupo $\mathrm{X}$ como organizadores da ação. Foram exibidos dois filmes, sendo o nosso o segundo. Não havia muita gente, era uma noite de segunda-feira de frio e chuva. Estavam presentes, basicamente, pessoas que faziam parte da ocupação, cerca de quinze espectadores. Após a exibição do primeiro filme e antes de começar o nosso, metade dos presentes, todos ligados ao grupo X, se retiraram da sala. 


\section{CONSIDERAÇÕES FINAIS}

Embora tenhamos trilhado caminhos já percorridos pela teoria antropológica em seu processo de reflexão sobre si mesma enquanto disciplina, acreditamos termos contribuído para o debate metodológico contemporâneo ao evidenciar como determinadas reflexões metodológicas ganham mais sentido quando derivadas das dificuldades encontradas na própria prática de pesquisa; ao tentar organizar as formas de pesquisa participativa, a luz de Peruzzo (2003); ao mostrar como alguns postulados metodológicos básicos da pesquisa participativa não podem ser esquecidos, tais como a imersão do pesquisador no universo pesquisado; e ao discutir as possibilidades de relação entre pesquisadores e pesquisados em situações em que estes estão organizados em grupos que estão em claro e aberto antagonismo entre si no universo em questão.

O processo de construção do conhecimento que experimentamos nos permite hoje distinguir três formas de fazer pesquisa participativa. Nos termos de Peruzzo (2003), temos a pesquisa de campo com observação participativa, a pesquisa participante e a pesquisa ação. A partir dessas possibilidades, estamos aptos a escolher com mais propriedade os métodos a serem adotados em nossas pesquisas em cada caso e a aprofundar os estudos acerca destes métodos. Para este aprofundamento, temos as referências de autores pós-colonialistas da antropologia, que questionam a autoridade etnográfica ${ }^{5}$; autores que discutem essa bibliografia, tais como Straterth (2013); e as proposições metodológicas mais recentes, tais como a de copesquisa, vista como um dos tipos de pesquisa ação (Cava, 2013; Cava e Machado,2013). Acredito que a partir dessas experiências acumuladas estejamos aptos a discutir com esses autores.

\section{REFERÊNCIAS}

BHABHA, Homi K. O local da cultura. Belo Horizonte: Editora da UFMG, 1998. BRANDÃO, Carlos Rodrigues. Pesquisa participante. São Paulo: Brasiliense, 1981. Repensando a pesquisa participante. São Paulo: Brasiliense, 1984.

\footnotetext{
${ }^{5}$ Ver Said (2011), Bhabha (1994), além dos já citados Clifford (1986) e Wagner (2010).
} 
CAVA, Bruno (2013). A copesquisa militante no autonomismo operaísmo. Lugar Comum, Rio de Janeiro: n³7-38, pp. 17-38, fevereiro,2013.

\& MACHADO, Cristina de Amorin(2013). Um estudo preliminar sobre o encontro entre a copesquisa e os science studies. Revista Brasileira de História da Ciência, Rio de Janeiro: v. 6, n. 2, p. 221-231, julho a dezembro, 2013

CLIFFORD, James. Writing Culture. California/USA: Universit of California Press, 1986.

FALS BORDA, Orlando. Aspectos teóricos da pesquisa participante: considerações sobre o significado e o papel da ciência na participação popular. In: BRANDÃO, Carlos Rodrigues (Org.) Pesquisa participante, pp.42-62. São Paulo: Brasiliense, 1981.

MALINOVSKI, Bronislaw. Argonautas do pacifico ocidental: um relato do empreendimento e da aventura dos nativos nos arquipélagos da Nova Guiné Melanesia. Coleção Os

Pensadores, v. 43. São Paulo: Abril Cultural, 1976.

PERUZZO, Cicilia Maria Krohling. Da Observação participante à pesquisa-ação: pressupostos epistemológicos e metodológicos. Intercom - Sociedade Brasileira de Estudos Interdisciplinares da Comunicação XXVI, Congresso Brasileiro de Ciências da Comunicação. Belo Horizonte. Anais - Minas Gerais, 2003;

SAID, Edward W. Cultura e imperialismo. São Paulo: Companhia das Letras, 2011.

STRATHERN, Marilyn. Fora de Contexto: as ficções persuasivas da antropologia. São Paulo: Terceiro Nome, 2013.

WAGNER, Roy. A invenção da cultura. São Paulo: Cosac Naify, 2010.

WEBER, Max. A “objetividade” do conhecimento nas Ciências Sociais. In: FERNANDES, Florestan. (Coord.); COHN, Gabriel (Org.). Max Weber. Sociologia. Tradução: Amélia Cohn e Gabriel Cohn. 6 ed. São Paulo: Ática, 1997. (Coleção Grandes Cientistas Sociais; 13).

VELHO, Gilberto. Individualismo e cultura. $3^{\text {a }}$ ed., Rio de Janeiro: Zahar, 1994. 
Marcelo Ernandez Macedo

Universidade do Estado do Rio de Janeiro

Professor Associado da Faculdade de Comunicação Social

Cooordenador do Laboratório de Comunicação Dialógica

\section{Artur Seidel Fernandes Bacharel em Ciências Sociais (Uerj). Ex-bolsista de extensão do
Laboratório de Comunicação Dialógica}

Jenifer Silva dos Santos Bacharel em Comunicação Social (Uerj). Bolsista de iniciação científica do Laboratório de Comunicação Dialógica

Esta obra está licenciada sob uma Licença Creative Commons. 